\title{
Transforming Bodywork in Eldercare with Wash-and- dry Toilets'
}

\section{Agnete Meldgaard Hansen}

Assistant Professor, Roskilde University, Department of People and Technology, Denmark ${ }^{2}$

\section{Sidsel Lond Grosen}

Associate Professor, Roskilde University, Department of People and Technology, Denmark

\begin{abstract}
This paper addresses how the introduction of welfare technologies in Denmark makes the bodywork of eldercare an object of public governance, and investigates how wash-and-dry toilets co-constitute professional care work. First, a theoretical frame is established for studying care, with an emphasis on bodywork as a sociomaterial and collective accomplishment. The paper then unfolds the great expectations tied to welfare technologies in general, and wash-and-dry toilets specifically. Turning to differentiated examples of situated uses of the toilets, the complexity of making the toilets work within the context of professional eldercare is illustrated. Some of the uses of the toilets in care work are in concordance with policy expectations. Other uses demonstrate difficulties in satisfying the great expectations and call for a more complex understanding of what it takes to achieve dignified, technologically assisted care without silencing the skills and professionalism of care workers.
\end{abstract}

\section{KEYWORDS}

Assistive technology / bodywork / care work / dirty work / eldercare policy / empowerment / sociomaterial practices / wash-and-dry toilets / welfare technology / welfare state reform

\section{Introduction}

elfare technologies are used in daily practice to a considerable extent in Denmark, compared to other Nordic countries (LGDK 2017; Mortensen 2015). This development is promoted through national policies, with expectations of a win-win relation between matters of economic efficiency, quality of service, and the self-reliance of citizens. Such improvements are largely expected to be generated at the very forefront of the welfare state, altering how care is performed in the daily encounters between care workers and care recipients (Thiim 2010).

Four specific welfare technologies were selected as strategic priorities in 2014-2016, one of them being wash-and-dry toilets. In January 2016, around 4600 wash-and-dry toilets were assessed to be in use in municipal care (The Government and LGDK 2013b; LGDK 2017). Wash-and-dry toilets are expected to facilitate empowerment of elderly citizens, who in using them may become more self-sufficient and thereby diminish their need for professional care (The Government et al. 2013). Moreover, it is argued that

\footnotetext{
${ }^{1}$ You can find this text and its DOI at https://tidsskrift.dk/njwls/index.

${ }^{2}$ E-mail: agmeha@ruc.dk; https://forskning.ruc.dk/da/persons/agmeh.
} 
wash-and-dry toilets improve the working environment of care workers, as the toilets are thought to minimize strenuous work positions (Ibid.).

The expected changes are closely related to the functionality of the wash-and-dry toilets and to their use in practical care work that may be understood as a form of 'bodywork' in the sense that the bodies of (in this case) elderly people become the object of care workers' labor (Wolkowitz 2002; Twigg et al. 2011). Yet, understandings and practices concerning care work must also be expected to be co-constituted by the use of technology (Orlikowski 2007; Mol et al. 2010; Gherardi \& Rodeschini 2016).

On this basis, we will examine how the bodywork of eldercare is constituted and negotiated in relation to both policy expectations and the everyday use of wash-and-dry toilets.

We will depart from theoretical discussions of bodywork and consider the tabooed character of work that might be characterized as 'dirty work' (Hughes 1962; Ashforth $\&$ Kreiner 1999) and relate these to discussions on the mutual constitution of technology and social practices in general, and care practices in particular (Orlikowski 2000; Gherardi \& Rodeschini 2016). We then unfold the great expectations and governance ambitions tied to welfare technologies in general, and to wash-and-dry toilets specifically. Turning to the use of wash-and-dry toilets in practical care, we show the difficulties of making the toilets function within the complex context of professional eldercare work. Through examples of situated uses, the paper illustrates how some uses are in concordance with policy expectations while others challenge them on different levels, while still changing the terms on which care work is performed.

\section{Understanding technologically assisted care work}

In the Scandinavian context, care work with elderly citizens has often been studied with a primary focus on the relational aspects of work (e.g., see Wærness 1984; Astvik 2003;). However, this type of care work is also (and perhaps increasingly) characterized by so-called 'bodywork'; an aspect often under-represented in accounts of professional care work (Twigg 2000b; Dahle 2005). Bodywork can be defined as 'work that focuses directly on the bodies of others: assessing, diagnosing, handling, treating, manipulating, and monitoring bodies, that thus become the object of the worker's labour' (Twigg et al. 2011). Bodywork with elderly citizens is often transgressive, as it involves intimate physical contact between citizens' and care workers' bodies, and interaction with sexualized and tabooed parts of the body and its functions; interaction that breaches normal social rules of intimate physical contact (Dahle 2005). Furthermore, the object of labor in eldercare, the elderly body, is a socially marginalized body related to cultural imageries of old age as a time of decay, dysfunction, lack of bodily self-control, and impurity - the so-called fourth age (Katz 1996; Isaksen 2002; Gilleard \& Higgs 2011). This type of work is of low social status and may be characterized as a form of 'dirty work' (Dahle 2005; Stacey 2005) - work that, though considered societally necessary, is culturally perceived as physically, socially or morally 'tainted' (Hughes 1962; Ashforth $\&$ Kreiner 1999). Workers in 'dirty' occupations face societal stigma, and consequently struggle to construct positive and 'esteem-enhancing' work identities in a variety of ways (Ashforth \& Kreiner 1999, 2014). In this light, eldercare work may be considered a lowstatus and stigmatized occupation (see also Laulainen \& Hujala 2016). 
However, studies of eldercare work in Denmark point to developments that contribute to a reframing of eldercare work in a more positive light. From the late 1960s onwards, Dahl (2005) has identified what she terms 'a will to the pleasant' in politicoadministrative discourses of eldercare in Denmark. She shows how the goals of eldercare services have shifted, from originally being expressed in negative terms of relieving loneliness and distress among elderly citizens, to focusing on more positively framed goals of promoting well-being, quality of life, and development. In line with this, Mikkelsen (2017) shows how a 'pursuit of pleasure' has become an integrated part of health promotion efforts in the Danish eldercare sector. Furthermore, Hansen (2015, 2016) shows how such positive reframings of eldercare contribute to a 'cleaning' and 'distancing' of concrete bodywork practices in care work with elderly citizens. Working with a new national policy, promoting rehabilitation, care workers physically withdrew from the transgressive and 'dirty' tasks of eldercare and conducted 'hands-off' bodily care at a distance. The studied care workers thus disassociated themselves from more traditional caring identities, and from the related dirty tasks and imageries of decaying bodies (Hansen \& Kamp 2018).

We will show how the use of wash-and-dry toilets in eldercare work adds to this development toward a more distanced and self-reliance-oriented provision of care for elderly citizens, and how this use addresses the transgressive and tabooed dimensions of eldercare. To understand the complexity of care work using wash-and-dry toilets, we draw on studies highlighting how work practice and technology are mutually constituted and negotiated in practice (Orlikowski 2000, 2007; Gherardi \& Rodeschini 2016). As Gherardi and Rodeschini (2016) phrase it, the work of caring must be seen as 'an ongoing socio-material accomplishment'. Highlighting the role of a multiplicity of human and non-human actors, they go on to define care as:

....an emergent process, a competence that is realized by a heterogeneous collective of more or less able-bodied humans, tools, technologies, rules and other 'non-humans' or 'more than humans' (Braidotti 2013) linked within sociomaterial relationships (Gherardi and Rodeschini 2016)

Drawing on this complex understanding of care, our study illustrates how care workers, citizens, their bodies, technologies, care ideals, policies, and expectations work together to accomplish bodily care in new manners when wash-and-dry toilets are introduced. An important point in the understanding of care in this manner is that the sociomaterial accomplishment of care by such a heterogeneous collective of actors will require so-called 'articulation work'. Articulation work is defined by Star and Strauss (1999) as 'work that gets things back on track' when something unexpected happens, and work that accommodates unanticipated contingencies (Ibid.). They emphasize that articulation work will often be invisible in formalized and rationalized accounts of work, and that therefore it will seldom be included in work plans and work descriptions.

Following these insights, both the actual use of technology and the expectations of it, which are rooted in broader developments of care ideals and care policies, are not only seen as co-constitutive of the day-to-day bodywork of eldercare but also as coconstitutive in the continuing construction of the content and purpose(s) of care work. This approach directly influences the methodology and design of our study. 


\section{Methodology}

Our research design combines a policy study with studies of the local use of washand-dry toilets at three work-sites. With this design, we focus on broad ideational developments in the eldercare sector, and the expression of expectations of the use of wash-and-dry-toilets in central policy documents. Furthermore, we focus on the use of wash-and-dry toilets in the local practices of eldercare, and their implications in matters of work content and purpose. We take inspiration from Shore and Wright $(1997,2011)$ and their concept of 'anthropology of policy', as we study 'small sites that open windows onto larger processes of political transformation' (Shore \& Wright 2011).

Our policy study includes texts produced by cooperative and governmental bodies at various levels of government in Denmark: the state, the regions, and the municipalities. We were specifically interested in texts that could be called 'prescriptive' or 'practical' - in the sense that they were written with the purpose of 'offering rules, opinions and advice', and thereby carry an intention of shaping practice (Foucault 1990 [1985], p. 12). In our case, this entails guidance and regulation issued by and for governmental and administrative bodies at various levels. Our archive of policy texts consists of 118 documents, collected through internet searches with central institutions in the field, combined with a snowball search strategy.

In addition to the documents, we have interviewed key informants at various levels of government: The head of the Center for Welfare Technology in the association of municipalities, Local Government Denmark (LGDK), and five key officials in the field of 'welfare technology' in municipalities in Denmark. Our document archive and interviews focus broadly on welfare technologies and the rationales behind their implementation. Wash-and-dry toilets are specifically in focus in only some documents and interviews. The analysis presented in this paper not only draws on these specific mentions of wash-and-dry toilets but also on the more general representations of welfare technologies.

Our studies of the use of wash-and-dry toilets were conducted in 2015-2017 as ethnographic field studies at three workplaces: an eldercare center that installed washand-dry toilets for selected residents (eldercare center 1); an eldercare center with wash-and-dry toilets installed in all apartments (eldercare center 2); and a homecare district with relatively easy access to the acquiring of wash-and-dry toilets. While, for example, Cohen-Mansfield and Biddison (2005) and Yachnin et al. (2017) have studied short-term uses of wash-and-dry toilets in an experimental setting, we have studied organizations with long-term use, that have thus moved beyond the inevitable 'teething troubles' of implementation processes. This allowed us to study how wash-and-dry toilets reconstituted bodywork in everyday eldercare practices.

Our studies in the three workplaces consisted of semi-structured interviews, shadow observations, and the reading of local documents on wash-and-dry toilets and welfare technologies. We conducted both group (9) and individual (11) interviews with employees and managers at the three workplaces, interviewing in total 35 individuals. Our shadow observations (Czarniawska 2007) were carried out as follow-alongs and ride-alongs with 17 employees on day, evening, and night shifts. On each occasion, we followed an employee for the duration of a shift as 'partly participating observers' (Fangen 2010), not participating directly in work activities, but observing practices and chatting informally with the people involved. Observations were recorded in 
short notes during the shifts and were shortly afterwards elaborated into fuller written accounts.

The primary staff groups working at the sites were social and health care aides and assistants, nurses, and occupational therapists and physiotherapists. In the analysis, we focus primarily on the social and health care aides and assistants, which are the primary staff groups performing practical care. In the following, these two groups will be collectively termed 'care workers'. We obtained consent for the research from the management responsible and the observed employees, and the research was conducted in accordance with the Danish Code of Conduct for Research Integrity. All individuals, workplaces, and municipalities have been made anonymous by using alternative names and blurring details that may lead to easy identification.

The policy analysis and the analysis of the use of wash-and-dry toilets are based on thematic coding of this extensive and multifaceted empirical material. In the policy analysis, the themes were objectives of implementation of welfare technologies generally and wash-and-dry toilets specifically; relations to other strategic priorities within eldercare; and ideals of eldercare. In the analysis of toilet uses, the themes were differentiation of use; organization of work; interactions between toileting and bodily and relational aspects of care work; and ideals of eldercare. The quotations and observations selected for presentation in the forthcoming sections have been chosen as examples of wider tendencies in the entire empirical material. Inspired by studies of 'technology-inpractice' that illustrate how the same technology may be involved in widely varied uses (Orlikowski 2000), we will show the varied situational uses of wash-and-dry toilets in professional care work. Although covering and relating multiple sites and levels, our study does not present general knowledge, directly applicable across contexts. Rather, we present context-dependent in-depth knowledge (Flyvbjerg 2006), carefully related to a specific national policy context, which may resonate with and be the cause for reflection in similar contexts where wash-and-dry toilets are used.

\section{Great expectations - the policy level}

Surfacing around 2008, the idea of welfare technologies rapidly gained currency at the national policy level as a solution to welfare state problems. The term was used for the first time in a parliamentary debate in April 2008, following a public/private conference and discussion paper that presented a group of technologies as potential solutions to welfare state problems (IDA \& LGDK 2008; Kier 2008). Welfare technologies quickly developed into a significant theme in Danish policymaking regarding health and social care (The Government \& LGDK 2011, 2012, 2013a). In policy documents, welfare technology is repeatedly presented as a solution to what would otherwise be considered very different problems: matters of economic efficiency, quality of service, the self-reliance of citizens, and the work processes and working environments of front-line personnel. The implementation of welfare technology is represented as creating a win-win situation, where all these matters are resolved simultaneously at the very forefront of welfare state services: in daily interactions between citizens and care workers.

For example, this understanding of welfare technology as a kind of catch-all solution appears in the following passage from the 2016 'Common Public Sector Digitalization Strategy': 
The large majority of citizens wish to live an active life, where they can take care of themselves in everyday life, and have the freedom to do the things they want. Digital welfare solutions play an important role in fulfilling that wish. [...] Disseminating digital welfare solutions that provide more freedom and makes the individual more self-sufficient is both a question of quality of life and of good socio-economics. (The Government et al. 2016, pp. 28-29)

Welfare technologies are thus expected to reduce the need for care services, resulting in both increased quality of life for citizens (a specific free, active, and self-sufficient version of this), and in reduced public expenditure on care. These expectations are in line with the described ideational developments in the eldercare sector focusing on rehabilitation, activation, freedom, and self-sufficiency to create what Dahl (2005) has termed 'a different form of retrenchment'.

Furthermore, welfare technologies are expected to transform the work of public sector employees. The most prominent expectation regarding such work is that welfare technologies will promote smarter and more efficient work processes, and reduce the need for labor in the sector. An example of this expectation is given in the 2009 description and naming of the government-financed 'foundation for investments in labor-saving technology' (the ABT foundation) that aimed to promote 'testing and dissemination of new labor-saving technology and new forms of work and organization in the public sector' (Ministry of Finance 2009). The foundation's name was later changed to 'the foundation for technology applied close to the citizens' (2010) and later again to 'the foundation for welfare technology' (2014). At first glance, these changes of name signal a change in focus, away from the rationalization of public services and work processes, toward more quality- and citizen-focused aims. Despite this seeming change in focus, rationalization, increased productivity, and labor-saving solutions have remained central aims in both the foundation deeds and in other policy documents (Ministry of Finance 2010, 2014; The Government et al. 2013, 2016).

Another transformation of the work of public sector employees expected from the use of welfare technologies is improvement of the working environment. This aim is less prominently featured in the policy archive than the above-described aims. Nevertheless, it is an integrated part of arguments for increased use of welfare technologies in some documents from central actors, for example, LGDK, the employers' organization for the municipal care sector. In their 'concluding measurement' of their joint program to disseminate welfare technologies, they write that with the increasing use of welfare technology, 'we protect and develop hands and heads across professional fields, as we make use of the technological opportunities to create a better working environment and more flexibility to carry out the tasks' (LGDK 2017). Welfare technologies are thus expected to improve both the psychosocial and the physical working environment for public sector employees (The Government et al. 2013).

As mentioned earlier, wash-and-dry toilets are one of four strategically prioritized welfare technologies. They are thus included not only in the general perceptions of the potential of welfare technologies but also receive specific attention in some documents. Here, more specific expectations are expressed of the use of this particular welfare technology. One set of expectations considers how the toilets will contribute to the abovedescribed aims of reducing labor and improving the working environment of front-line care workers. Where other technologies are expected to contribute to solving care tasks, 
for example, by making work processes more efficient or less physically demanding, the wash-and-dry toilets are expected to partly or completely eliminate the care task from the daily worksheets of care workers. There is an expectation that the task can be (partly) automated and taken over by the technology and the self-sufficient citizen in cooperation, leaving the care worker to tend to other tasks and avoiding the physical strain of 'regular' assistance for toileting. These expectations are translated into concrete measurement tools, which can help municipalities to calculate potential savings in, for example, labor time and transport to citizens' homes (Center for Welfare Technology 2014).

Another set of expectations of wash-and-dry toilets can be seen as slightly different from the general expectations of welfare technologies, as they are related to the very intimate care task the toilets are supposed to carry out. In the policy documents, the washand-dry toilets are associated with matters of dignity and dignified care interactions. For example, in an evaluation of a project testing wash-and-dry toilets in four municipalities, we find the following connection being made between wash-and-dry toilets and dignity: 'Where the wash-and-dry toilet is relevant for the citizen, the wash-and-dry toilet contains great potential, both in terms of the citizen's self-sufficiency and dignity...' (Rambøll 2012 p. 6). Using a wash-and-dry toilet is considered more dignified for the citizen than receiving help from a care worker when going to the toilet. The same rationale is expressed in a report on citizens' attitudes toward digital welfare. In this report, citizens were asked: 'Do you have a positive attitude towards using the following welfare technology, if you had the need and opportunity to: an automatic toilet that can washand-dry without the help of human hands?' (The Digitalisation Administration 2013). The use of the toilets is thus framed as aiming to avoid the 'help of human hands'. Furthermore, in the above-mentioned evaluation, care workers in the municipalities were asked if they found it 'pleasant' no longer having to take care of citizens' 'lower hygiene' (Rambøll 2012, p. 10). These ideas of dignified self-sufficiency and nonintervention of human hands in intimate bodily areas correspond with the described development in the field of Danish eldercare toward less 'dirty' and more 'pleasant', distanced, handsoff forms of bodywork (Hansen 2015, 2016). The wash-and-dry toilets are envisioned as helping citizens and care workers to avoid unpleasant and tabooed transgressions of bodily boundaries in care interactions, and are seen as a more dignified way of getting the task done.

In sum, the policy papers express an ideal of freedom and dignity for citizens, achieved through technologically assisted increased self-sufficiency, and the noninterference of care workers in the citizen's intimate bodily areas. This ideal goes hand in hand with an ambition to rationalize frontline care services and, less prominently, to improve the working environment of frontline personnel. Together, these ideals and ambitions prepare the ground for care practices, where care workers have less contact with and maintain greater physical distance from citizens. This stands in stark contrast to previous discourses and ambitions in the sector, where social contact and the presence of sufficient numbers of 'warm hands' (care workers) to help elderly citizens were seen as important to the quality of care services (Dahl 2000; Hansen \& Pedersen 2014). The ideal expressed in the policy documents is instead one where (publicly funded) care is as far as possible absent from citizens' lives, and the task of attending to bodily needs is taken over by citizens themselves and automatic technology. The specific task of assisting elderly citizens in going to the toilet is cast as a quite simple and practical operation that is easily transferable to a machine. 


\section{Situated uses of wash-and-dry toilets}

Our study of the use of wash-and-dry toilets in professional practice challenges the policy expectation of reducing labor through a relatively unproblematic shift of tasks from human actors to automated washing and drying. Instead, post-toilet hygiene is exposed as a complex task that is not so easily rationalized.

On the basis of our shadow observations and interviews at the workplaces, we will in the following, first, unfold issues concerning the functionality of wash-and-dry toilets in relation to complexities of post-toilet hygiene in professional eldercare. Second, we will show how the multiple, situated uses of the toilets change care work in ways that are not always in accordance with policy expectations.

\section{Functionality of wash-and-dry toilets in professional practice}

A wash-and-dry toilet is pretty accurately named. It is a toilet that washes and dries a person's intimate parts when sitting on it. It is normally used after urinating or defecating and is activated by a panel mounted close to the toilet, or by a remote control, or by pressing an on/off button. It is possible to choose between various options and to adjust the water temperature. The toilets normally have built-in heating in the seat.

While Gherardi and Rodeschini argue that care is a collective accomplishment, including humans as well as nonhumans (Gherardi \& Rodeschini 2016), our interviews and observations across the sites reveal that the functionality of toilets is also a matter of sociomaterial cooperation and not just of technological design. A toilet's features, elderly bodies, and professional assessment all play an important role in this.

First, satisfactory use of the toilets makes some demands on the user's mobility. Common models of wash-and-dry toilets operate by advancing a small pipe beneath the person sitting. The pipe first sprinkles water, and afterwards blows warm air. Although the pipe does have some back and forth movement, care workers call attention to the need for users to be positioned with some precision, and to be sufficiently mobile to catch the jet of water by moving a little. As users who are not able to wipe or wash themselves lack mobility, this is not always possible.

Second, as was brought up repeatedly by care workers in our studies, the optimal functionality of the toilet can be limited by the shape of the user's body. For example, the buttocks of obese users are squeezed together by the toilet seat, and so the water cannot reach the areas it is supposed to clean. Or, if a user is very small and skinny, water might squirt up the user's back, which is messy and undignified. Moreover, if the user's skin is wrinkled, dirt can become caught in the wrinkles and the skin sometimes does not dry properly. As drying takes quite some time, this part of the process has its own problems. Some users become impatient, while others cannot sit on the toilet long enough without getting sore.

Third, the use of the toilets poses cognitive demands. Optimally, the user should be able to operate the panel. As care workers' accounts of mishaps make clear, the user should as a minimum be able to understand that water and air is coming, or at least to cope with it happening.

These considerations concerning the match between potential users and toilets are negotiated in relation to professional responsibilities for practical care, health, dignity, 
and wellbeing. While the toilets are considered to diminish occurrences of urinary tract infections and rashes in some cases, they might cause fungal infections in others, or might not clean the user sufficiently. Although often overlooked or silenced due to its relation to the transgression of normal boundaries of physical contact (Dahle 2005), post-toilet hygiene hereby becomes visible as a professional matter.

Finally, maintenance (e.g., descaling the jet), knowledge, and awareness of primary functionality among the care professionals and/or users is a precondition for upholding the toilets' functionality.

All in all, the body and bodywork become central in the use of technology in professional care work. Being part of situated sociomaterial relationships, the elderly bodies, the professional practices, and the toilets all play their parts in constituting if and how the wash-and-dry toilets are used, and how they influence the work of the care professionals.

In the following, we will analyze various uses of the wash-and-dry toilets and how they constitute bodywork in eldercare differently.

\section{Preventing or eliminating the need for professional care}

Some uses of the wash-and-dry toilets are characterized by the absence of professional care work. Being the most direct extension of the policy expectations, these are uses where the need for professional care is prevented or eliminated as the citizens become self-reliant by way of using wash-and-dry toilets. According to our interviews with management and administration, this group includes citizens who have previously received care but who no longer need it due to wash-and-dry toilets, but also includes, for example, the spouses of those users, whose need for professional care is eliminated or deferred.

Although care workers in a survey express some concern over loss of jobs due to welfare technology (Hansen \& Larsen 2017), no such concern is expressed in our studies. This absence of concern is preconditioned by a continuous transfer of tasks from hospitals to the secondary care sector, which has taken place over the last decade in Denmark, and which increases both the amount and complexity of tasks under municipal care (LGDK et al. 2017). That the absence of tasks related to the toilets is not bemoaned can also be seen in relation to the cultural imagery of the 'fourth age' with its unattractive elements of decay, dysfunction, and lack of bodily self-control (Gilleard \& Higgs 2011). The loss of ability to go to the toilet oneself may be perceived as a transition to this phase of life. Even though they do not postpone bodily decay, wash-and-dry toilets defer the loss of control over the toilet situation, which is often depicted as central to a person's sense of dignity and normality. Concurrently, professional care work retains fewer tasks associated with 'dirty work' (Ashforth \& Kreiner 1999, 2014), as the care worker is not involved in the toilet situation at all.

\section{Avoiding unease in the professional care relation}

Often wash-and-dry toilets do not eliminate the need for professional care, but substitute elements of it; for example, when elderly citizens are unable to get to the toilet or to pull up their trousers by themselves. Still, wash-and-dry toilets are used to perform tasks 
and to ease the situation. An example of this appeared in our homecare case, where one of the authors shadowed the care worker, Lizzy, as she visited a citizen, Elsa:

Lizzy starts by waking Elsa gently and introduces me. Lizzy tidies the bedroom a little and puts down the bed's guard rail. I follow her to the kitchen where she puts on coffee and tidies up. Elsa calls for support to get on socks and slippers. After this, she moves herself to a wheelchair standing by the bed. Lizzy arranges Elsa's nightgown to facilitate her transfer to the toilet afterwards, instructs her to lift her legs and pushes the wheelchair to the bathroom. Leaning on the toilet's armrests, Elsa gets to her feet, Lizzy removes her incontinence pad, and Elsa places herself on the toilet. Lizzy leaves the room. Standing outside the bathroom, I can hear the wash-and-dry toilet working. Elsa asks for toilet paper, which Lizzy fetches. She asks if the toilet has finished drying. Elsa answers that it has, but it does not dry so well. Lizzy mentions to her that one has to sit for quite a while for it to dry properly, but Elsa objects that she cannot sit for so long without pain. Chitchatting, Lizzy now helps her get dressed. Later, Lizzy tells me that without the toilet, Elsa would probably have to be washed in bed. (Observations, homecare)

At first glance, it does not appear that the toilet eliminates tasks or time-use from care work. As Elsa still needs help, a lot of what Star and Strauss (1999) term 'articulation work' is still needed to facilitate the use of the toilet. Nonetheless, as Lizzy explained, the toilet substitutes the labor-intensive task of washing Elsa in her bed. Washing a person in bed takes time, as it involves numerous subtasks, and demands extended cooperation between care worker and care recipient to minimize physical strain for the care worker. Use of the wash-and-dry toilet changes the tasks involved in the bodywork of care and decreases physical strain in the specific care event. Although the interaction concerning the tabooed situation is not eliminated, the boundary-transgressing element of the work is eliminated, diminishing the 'dirty' elements of work.

Apart from removing physically demanding and time-consuming tasks, the substitution of elements of human work with work done by the toilets is also used to remove tasks that put pressure on the relational aspects of care work - as shown here in relation to the citizen Agnes:

Agnes has used wash-and dry toilets for a long time. As her physical condition has worsened, so that she has to use an over-toilet-chair [that is incompatible with the wash-anddry function], the wash-and-dry toilet is about to be removed. She was self-reliant when going to the toilet and tells me that she misses being able to use it. Suzan [the care worker I am shadowing] later tells me that it "was so good for her, as it gave her an enormous freedom". She also tells me that it made their visits to Agnes shorter and more pleasant. It appears that Agnes was annoyed by her need for help and therefore hostile towards the care workers. Now Agnes needs three visits a day and help in going to the toilet. (Observations, homecare)

For Agnes, who misses being able to use it, and for the form of care work needed to support her, the termination of the use of the wash-and-dry toilet becomes a marker of transition to 'the fourth age' and the increased need for help begins to appear as a transition to a poorer quality of care. 
Suzan, simultaneously emphasizing the benefits for the care recipient, makes clear how the use of the toilet removed relationally straining tasks. She draws on discourses of being self-sufficient and uses them to argue for the benefits of some withdrawal of practical human care. Whether eliminating tasks in relation to intimate hygiene or not, the examples demonstrate how the wash-and-dry toilets partake in reconstituting the bodywork of care, and become part of the more general shift toward 'cleaning' and 'distancing' in the practices of eldercare in Denmark (Hansen 2016).

\section{Using the toilet for reconfiguring dementia care}

The field of application for wash-and-dry toilets is not only limited to age-related disabilities but also expanded. An example of this is the use of wash-and-dry toilets for reconfiguring dementia care in eldercare center 1 . As described in relation to their functionality, the use of the wash-and-dry toilets requires some cognitive ability. Therefore, dementia care might not seem an obvious field of application. Nonetheless, the staff at the center saw it as a way to diminish conflicts in dementia care, such as physical resistance, verbal aggression, or violence against the care worker in situations concerning post-toilet hygiene:

To residents with dementia these care tasks could be perceived as offensive, and as something they did not want to be part of. It formed the basis of conflicts in the care work. (Self-evaluation report on technology use, eldercare center 1)

Not all residents with dementia are taught to use the toilets, as some are startled when the toilet starts washing. Residents with dementia who accept the toilet are taught to use it themselves, or instructed in its use when they go. Apart from reminding residents to use the wash-and-dry function when already helping them to go to the toilet, the process demands that care workers be attentive and react swiftly when observing that a resident with dementia needs to go to the toilet. This affects their other care tasks, as they must interrupt what other work they might be doing to assist a resident with dementia in learning to use the wash-and-dry function. This is a time-demanding process that can go on for months, and again, extensive articulation work is involved. The effort is sometimes futile due to the residents' inability to remember what they learn, and the effort to teach residents to use the toilet by themselves is sometimes replaced by a routine where the care worker turns on the washing and drying function.

The use of the toilets to minimize conflicts and improve relations while still getting the tasks done appears to be meaningful but time-consuming. In continuation of Orlikowski's (2000) conceptualization of technology as 'technology-in-practice', it illustrates how the use of welfare technologies such as wash-and-dry toilets, through practical use and experimentation, develops through practice in ways that are not presupposed in policies. Yet, the process of teaching a resident with dementia is time-consuming, while the time saved by avoiding conflicts is difficult to account for. The use of washand-dry toilets to reconfigure dementia care is thereby in continuation of policy ideals concerning dignity, quality in care, and working environment, but less so in relation to expectations of increased efficiency and reducing labor. 


\section{A bit of luxury}

Another example of the situated use of the toilets is their enrollment in some care workers' attempts to provide experiences of wellbeing and 'luxury' in everyday life for the elderly citizens. Again, we see a practice-based expansion of what kind of technology a wash-and-dry toilet is, and of what it may be used for.

The most prominent example of this type of use is also from our observations at eldercare center 1 . One of the authors shadowed a care worker, Jeanette, for a day. In the course of the day, it became evident that Jeanette thought of her work as being aimed at creating a calm, comfortable, and enjoyable everyday life for the residents she cared for, most of them suffering from dementia. This related to the overall values at the center, aiming at creating 'a meaningful everyday life' for residents (Interview with center management). Jeanette described how some of the residents really enjoyed using wash-anddry toilets, and how they found them 'luxurious'. This feeling of enjoyment or 'luxury' related to the toilets was also noted in one of the observed care situations:

Jeanette and I go to Maren's apartment to help her out of bed. Jeanette walks to the bathroom with her, supporting her as they go. After Maren is safely seated on the wash-anddry toilet, Jeanette exits and closes the door behind her. Then it's more private for Maren, she tells me. Shortly after, Maren says that she's done using the toilet. Jeanette enters the bathroom again. Maren has started wiping herself with toilet paper, but Jeanette convinces her to use the toilet's washing function. "Let's just let this smart thing wash you", she says. Jeanette instructs Maren in how to sit correctly on the toilet - that is, to the back of the toilet seat, so the water will hit the right spots and clean her properly. When she is positioned correctly, Jeanette pushes the on-button for Maren. The toilet starts washing. Maren seems to be enjoying it and is smiling broadly. "This is fun!" she exclaims. When the toilet is done washing, Maren wipes herself with toilet paper, guided by Jeanette. They do not use the drying function, as it does not do the job properly, Jeanette later tells me. (Observations, eldercare center 1)

It is clear that using the wash-and-dry toilet did not save time or labor. Actually, the act of going to the toilet in this case takes longer and requires more (articulation) work, because Jeanette encourages the use of the washing function. Quite a lot of assistance is needed to position Maren correctly, turn the toilet on, and finally to dry her backside. However, to Jeanette and her colleagues, this seemed not very important when deciding whether or not a toilet should be used for a specific resident. As Jeanette explained in our interview, the decision of whether or not to use a wash-and-dry toilet was made based on the resident's 'tastes and needs'. In other words, the toilets were not thought of only as efficient or not efficient in cleaning specific elderly residents after urinating or defecating. The residents' experience of using the toilets was also important. It had to be to the resident's taste, something enjoyable and perhaps even 'luxurious'.

This connection between the wash-and-dry toilets and experiences of enjoyment, pleasure or luxury was not unique to the eldercare center described above. A care worker in our homecare case, for example, related how she had tried a toilet herself, to see how it felt for the citizens. She also described it as pleasurable. Furthermore, the toilets were described as more comfortable than regular toilets, because of the heated seats. In line with this mode of use, it is worth noting that automatic toilets are not only marketed as 
assistive technologies for elderly and disabled persons. They are in some contexts (so far primarily in Asia) also marketed as high-end luxury toilets (Ludacer \& Stenovac 2015).

This use of the toilets clearly draws on the turn toward pleasure and 'the pleasant' in eldercare (Dahl 2005; Mikkelsen 2017). As such, it is part of the agenda of promoting quality of life for elderly citizens. However, the pursuit of pleasurable experiences and 'luxury' described above seems to express a different interpretation of quality of life than the notions of self-sufficiency and independence that are prominent in policy discourses on welfare technologies. It is an interpretation of quality of life that does not necessarily yield cost reductions, but aims to create enjoyment and pleasure in an often not very enjoyable period of life, the fourth age. Furthermore, this use of the toilets may also be seen as a way of making a necessary act more pleasurable (cf. the above section on avoiding unease in the care relation), and as a way of working with what is at hand to create moments of enjoyment and luxury in a care sector that is otherwise starved of resources and very focused on 'prioritizing' - in the sense of providing only 'necessary' care services meeting 'real needs' (see Hansen 2015).

\section{Extensive nonuse}

In the previous examples, we have shown that while the uses of wash-and-dry toilets sometimes support the policy agenda of preventing or eliminating needs for professional care, the toilets are also used for other purposes, sometimes contradictory to policy expectations. However, as interesting as the above is, there is also extensive non-use of wash-and-dry toilets in situations where they are physically present or relatively easily available. This was most notable in eldercare center 2, which has wash-and-dry toilets in all 60 apartments. One of the authors shadowed three care workers in three parts of the center and notes:

The toilets appear to be used very little. During the three shifts, I have experienced washand-dry toilets in use twice and (probably mainly because I was present to observe the use of the toilets) two further residents were asked if they wished to use the washing function. Further two residents are reported to be self-reliant using the wash-and-dry toilets.

(Observations, eldercare center 2)

Use and nonuse was discussed with care workers in a group interview and in conversation with a physiotherapist at the center. Nonuse may be partly explained by the reluctance of some care workers, who were dissatisfied with the cleaning ability of the toilets (see also Cohen-Mansfield \& Biddison 2005) or by the fact that many of the residents were not able, bodily or cognitively, to use the toilets. The physiotherapist at the center added that the use of the wash-and-dry function had declined due to changed policies in the municipality; there had been a deliberate effort to make elderly citizens stay in their own homes for as long as possible. One consequence was that age-related disabilities were often quite progressed when citizens moved into the center. In sum, the toilets, elderly bodies with specific disabilities, and care workers could often not be assembled to achieve a viable 'collective accomplishment of care' (Gherardi \& Rodeschini 2016). The staff experienced a mismatch between the residents' bodies and cognitive disabilities on one side, and the functionality of the toilets on the other. In this situation, the physical 
and cognitive disabilities hinder the use of the technology, and care worker support is needed instead.

The organization of work at the center also appeared to play a role in the nonuse of the wash-and-dry toilets. Printed schedules with their tasks of the day were handed out to care workers at the beginning of their shifts. The schedules were full, and following care workers on their shifts, the pace was constantly high. During our observations at the center, the staff hardly ever sat down with the residents. In line with this, the manager explained that the center was known for its efficient use of resources. Work at the center was organized according to a principle of 'the whole center as one team' (Interview with center management). This meant that care workers from day to day could be allocated variable tasks with different residents in different sections of the center, as opposed to having a regular schedule with more or less the same residents, or at least residents in the same ward, every day. Knowledge of the individual residents and their daily routines thereby appeared to be affected. Consequently, knowledge of whether an individual resident preferred to use the wash-and-dry function was limited, time for experimenting was sparse, and the personal continuity needed for training in the use of the toilets was limited.

Despite their omnipresence, wash-and-dry toilets thus did not appear to have much influence on the bodywork at the center, as the wash-and-dry function remained mostly unused.

\section{Situated uses of wash-and-dry toilets}

To sum up, our studies of the uses of wash-and-dry toilets in professional eldercare show them to be quite differentiated 'technologies-in-practice' (Orlikowski 2000), dependent on the situational use and the network of actors involved (Orlikowski 2000, 2007; Gherardi \& Rodeschini 2016). Although perhaps not very surprising to scholars of technology in working life or working life studies in general, this picture contradicts the rationales and expectations that appear in policy documents. First of all, the complexity of the task intimate hygiene in collaboration with the differentiated bodies and abilities of the elderly potential users - calls for different professional approaches. Different local attitudes toward care and the functionality of the toilets also contribute to a differentiation of toilet uses. The different uses of the wash-and-dry toilets in professional practice spans uses that support the policy expectations, some other uses that partly support them, some that draw on different ideals of care, as well as extensive nonuse. While changing the performance of the care task, the differentiated uses of the wash-and-dry toilets challenge the assumption of an automatic rationalization of front-line care work as a consequence of implementing the toilets. Yet, it is also noticeable how ideals of freedom and dignity for citizens, achieved through technologically assisted increased self-sufficiency, and the noninterference of care workers in a citizen's intimate sphere, are present in practice. This is not necessarily because of the toilets, but in accordance with and supported by some uses of them.

\section{Concluding discussion}

We have approached the study of wash-and-dry toilets in eldercare work through an analytical lens, emphasizing the elements of this work that may be characterized as 
bodywork (Twigg 2000b; Wolkowitz 2002) and dirty work (Hughes 1962; Ashforth \& Kreiner 1999), and the potentially transgressive character of this work for both care recipients and care workers (Dahle 2005). Furthermore, we have drawn on an understanding of care as a sociomaterial accomplishment, carried out by a heterogeneous collective of human and nonhuman actors (Gherardi \& Rodeschini 2016). Moreover, our approach emphasizes the importance of broad developments in policy and ideation in the field of eldercare, as these are seen as co-constituting local care practices. However, we also emphasize how a seemingly simple technology such as a wash-and-dry toilet may be used in varied and unexpected ways, not necessarily in line with policy expectations, when entering situated practices of care - here they become complex technologiesin-practice (Orlikowski 2000).

With this framework, and based on empirical studies of policies and practices related to wash-and-dry toilets, we have shown how the bodywork of eldercare is constituted in relation to both policy expectations and the everyday use of the toilets. In our study of central policy documents, we have shown how wash-and-dry toilets are expected to enter local care practices and replace, partly or completely, 'the help of human hands' in post-toilet hygiene for elderly citizens. The task is constructed as simple and easy to automate. This automation of care tasks is expected to yield a number of benefits: reduced expenditure for time and labor spent on care, more dignified and self-sufficient lives for elderly citizens, and a better working environment for care workers after the removal of this strenuous work.

Our studies of local practices at two eldercare centers and one homecare unit show quite varied practices concerning the use of the wash-and-dry toilets - practices that support the above described policy expectations, some practices that partly support them, some that draw on different ideals of care, and some practices where the toilets are simply not used. Our study of situated practices thus shows a multiplicity of expected and unexpected uses of wash-and-dry toilets, and also shows that toileting and posttoilet hygiene is not just a simple manual task - it does not simply consist of a hand that washes and wipes. Achieving satisfactory intimate hygiene for elderly citizens in need of care requires professional skill and reflection. Getting and keeping wash-and-dry toilets into use by citizens is not a simple task, either. Often care worker intervention is not completely eliminated, so wash-and-dry toilets become part of the collective of actors accomplishing care, but do not replace care workers. Including wash-and-dry toilets in care interactions around toileting requires extensive articulation work (Star \& Strauss 1999) on the part of care workers. For example, it includes work to achieve and maintain the individual match between a uniform technology and elderly bodies of various sizes, with wrinkles, decreased mobility, etc. Care workers must provide the necessary professional support (e.g., instruction, assistance in physical positioning, drying, etc.) if they are to make the care arrangement work in a dignified and hygienically satisfactory manner.

These insights can contribute to reflection among both policymakers and local practitioners. The allure of wash-and-dry toilets in eldercare is clear. Intimate hygiene is a tabooed and transgressive part of care work, and it seems attractive to have a technology do the job, and save everyone involved the time and embarrassment related to this intimate and 'dirty' bodywork. However, a problematic assumption reducing professional care for toileting to 'a hand that washes and wipes' is embedded in this seeming 'technological fix' of an uncomfortable and time-consuming care task. Intimate bodily 
care is a tabooed and silenced task that few people, including professionals themselves, wish to discuss (e.g., see Diamond 1992; Twigg 2000a). The construction of the task as a simple manual task that may easily be automated risks contributing further to this silencing by overlooking its complexity and the professional skills and reflections required. Furthermore, the notion that 'the help of a human hand' in matters of intimate hygiene is undignified is also problematic, as it casts as undignified those care encounters where this is still a necessity. This risks worsening the taboo, adding to the feeling of loss, and 'othering' related to the fourth age for citizens (Gilleard \& Higgs 2010; Higgs \& Gilleard 2014), and risks adding to the stigma related to intimate and 'dirty' bodywork for care workers.

Moreover, the assumption that the task of post-toilet hygiene may simply be automated is also problematic, because it leads to seemingly quite exaggerated policy-level expectations of savings in time and labor. These expectations may have negative consequences in the organizations using and planning the use of wash-and-dry toilets, as they do not take into account the articulation work required to make the toilets work. This work is largely invisible in municipal budget-planning practices, where calculations are made in advance of the savings potential of wash-and-dry toilets. The discrepancy between this predictive budgeting and the unpredictable situated uses and practices related to wash-and-dry toilets contains a risk of intensification of care work, in cases where the wash-and-dry toilets do not yield the expected savings, but where the budget has already been cut. Furthermore, as we saw in eldercare center 2, there is a risk of extensive nonuse of the toilets if the planning of time and work is not adjusted to allow for sufficient continuity and time for experimentation with the technology in day-to-day care practices.

Finally, our argument in this paper is not against the use of wash-and-dry toilets, or that they may provide more dignity and self-sufficiency while also saving time and reducing labor in eldercare in some cases. Instead, we argue for a more complex understanding of what it takes to achieve dignified technologically assisted care - an understanding that includes and supports, rather than further silences, the skills and professionalism of care workers in carrying out post-toilet intimate hygiene, with or without the use of wash-and-dry toilets.

\section{Acknowledgments}

The research presented in this paper was funded by the Danish Working Environment Research Fund.

\section{References}

Ashforth, B. E. and Kreiner, G. E. (1999). “'How Can You Do It?': Dirty Work and the Challenge of Constructing a Positive Identity", The Academy of Management Review, 24(3):413-434. doi: http://dx.doi.org/10.2307/259134.

Ashforth, B. E. and Kreiner, G. E. (2014). "Dirty Work and Dirtier Work: Differences in Countering Physical, Social, and Moral Stigma”, Management and Organization Review, 10(1):81-108. doi: http://dx.doi.org/10.1111/more.12044. 
Astvik, W. (2003). Relationer som arbete. Förutsättningar för omsorgsfulla möten i hemtjänsten. [Relationships as work. Preconditions for caring encounters in homecare], Stockholm.

Center for Welfare Technology (2014). Vasketoiletter - Værktøjer og vejledninger [Washing-toilets - tools and guides, Copenhagen.

Cohen-Mansfield, J. and Biddison, J. R. (2005). "The Potential of Wash-and-Dry Toilets to Improve the Toileting Experience for Nursing Home Residents", The Gerontologist, 45(5):694-699. doi: https://doi-org.ep.fjernadgang.kb.dk/10.1093/geront/45.5.694.

Czarniawska, B. (2007). Shadowing, and Other Techniques for Doing Fieldwork in Modern Societies, Copenhagen: Copenhagen Business School Press.

Dahl, H. M. (2000). Fra kitler til eget tøj - Diskurser om professionalisme, omsorg og køn [From smocks to private clothes - discourses on professionalism, care and gender], Institut for Statskundskab, Aarhus Universitet.

Dahl, H. M. (2005). "A Changing Ideal of Care in Denmark: A Different Form of Retrenchment?" in Dahl, H. M. and Eriksen, T. R. (eds.) Dilemmas of Care in the Nordic Welfare State - Continuity and Change, Aldershot: Ashgate,:47-61.

Dahle, R. (2005). "Dirty Work in a Norwegian Health Context (The Case of Norway)" in Dahl, H. M. and Rask Eriksen, T. (eds.) Dilemmas of Care in the Nordic Welfare State Continuity and Change, Burlington: Ashgate:101-111.

Diamond, T. (1992). Making Gray Gold, University of Chicago Press.

Fangen, K. (2010). Deltagende observasjon [Participant Observation]. 2nd edition, Bergen: Fagbokforlaget.

Flyvbjerg, B. (2006). "Five Misunderstandings About Case Study Research", Qualitative Inquiry, 12(2):219-245. doi: http://dx.doi.org/10.1177/1077800405284363.

Foucault, M. (1990). The History of Sexuality vol. 2: The Use of Pleasure, New York: Vintage Books.

Gherardi, S. and Rodeschini, G. (2016). "Caring as a collective knowledgeable doing: About concern and being concerned", Management Learning, London: SAGE Publications Sage UK, 47(3):266-284. doi: http://dx.doi.org/10.1177/1350507615610030.

Gilleard, C. and Higgs, P. (2010). "Aging without agency: Theorizing the fourth age”, Aging \& Mental Health, 14(2): 121-128. doi: http://dx.doi.org/10.1080/13607860903228762.

Gilleard, C. and Higgs, P. (2011). "Ageing abjection and embodiment in the fourth age”, Journal of Aging Studies, 25(2):135-142. doi: http://dx.doi.org/10.1016/j.jaging.2010.08.018.

Hansen, A. M. and Pedersen, M. H. (2014). "Vidensproduktion, positionering og magt i historieværksteder [Knowledge production, positioning and power in chronicle workshops]", Tidsskrift for Arbejdsliv, 16(3):23-37.

Hansen, A. M. (2015). Rehabilitating Elderly Bodies and Selves - New Forms of Care Work, Professional Identity and Status in Rehabilitative Home Care, Roskilde University.

Hansen, A. M. (2016). "Rehabilitative bodywork: Cleaning up the dirty work of homecare", Sociology of Health and Illness, 38(7):1092-1105. doi: http://dx.doi.org/10.1111/14679566.12435.

Hansen, A. M. and Kamp, A. (2018). "From Carers to Trainers: Professional Identity and Body Work in Rehabilitative Eldercare”, Gender, Work and Organization, 25(1):63-76. doi: http://dx.doi.org/10.1111/gwao.12126.

Hansen, L. O. P. and Larsen, A. T. (2017). Velfærdsteknologi [Welfare Technology], København.

Higgs, P. and Gilleard, C. (2014). "Frailty, abjection and the 'othering' of the fourth age", Health Sociology Review, 23(1):10-19. doi: http://dx.doi.org/10.5172/hesr.2014.23.1.10.

Hughes, E. C. (1962). “Good People and Dirty Work," Social Problems, 10(1):3-11. doi: http://dx.doi.org/10.2307/799402.

IDA and LGDK (2008). Debatoplæg om teknologi i velfærden [Discussion paper on technology in welfare], Copenhagen. 
Isaksen, L. W. (2002). "Toward a Sociology of (Gendered) Disgust Images of Bodily Decay and the Social Organization of Care Work", Journal of Family Issues, 23(7): 791-811. doi: http://dx.doi.org/10.1177/019251302236595.

Katz, S. (1996). Disciplining Old Age: the Formation of Gerontological Knowledge, Charlottesville: University Press of Virginia (Knowledge, disciplinarity and beyond).

Kier, V. (2008). Ordførertale for KF vedrørende B 56: Forslag til folketingsbeslutning om en national handlingsplan for det medicinske område; d. 03.04.2008 [Spokesman speech for KF regarding B 56: Suggestion for a parliament decision on the medical area; 03.04.2008], Danish Parliament.

Laulainen, S. and Hujala, A. (2016). "Material Construction of Care Workers' Identity", Nordic Journal of Working Life Studies, Roskilde University, 6(S1):7-25. doi: 10.19154/ njwls.v6i1.4883.

LGDK (2017). Slutmåling. Det fælleskommunale program for udbredelse af velfærdsteknologi [Concluding measurement. The joint municipal program to disseminate welfare technology], København.

LGDK, Danish Regions and The State (2017). Afrapportering - Udvalg om det nære og sammenhængende sundhedsvæsen [Report - Committee for the near, local and integrated healthcare system].

Ludacer, R. and Stenovac, T. (2015). NeoRest \$10,000 luxury hi-tech toilet, Business Insider, Available at: http://www.businessinsider.com/neorest-10000-luxury-hi-tech-toilet-201512 ? $\mathrm{r}=\mathrm{US} \& I R=\mathrm{T} \& I R=\mathrm{T}$. Accessed February 9, 2018.

Mikkelsen, H. H. (2017). "Never too late for pleasure: Aging, neoliberalism, and the politics of potentiality in Denmark", American Ethnologist, 44(4):646-656. doi: 10.1111/ amet.12563.

Ministry of Finance (2009). Bekendtgørelse om Fonden til investering i arbejdskraftbesparende teknologi (ABT-fonden) [Foundation for investments in labor-saving technology Act].

Ministry of Finance (2010). Bekendtgørelse om ABT-fonden - Anvendt Borgernær Teknologi [Foundation for technology applied close to the citizens Act].

Ministry of Finance (2014). Bekendtgørelse om Fonden for Velfærdsteknologi [Foundation for Welfare Technology Act].

Mol, A., Moser, I. and Pols, J. (2010). "Care: putting practice into theory” in Mol, A., Moser, I., and Pols, J. (eds.) Care in Practice. On tinkering in Clinics, Homes and Farms, Bielefel: transcript Verlag: 7-26.

Mortensen, K. U. (2015). "Nordens velfærd hviler på danske skuldre” [The Nordic Welfare Rests on Danish Shoulders], Altinget. http://www.altinget.dk/velfaerdsteknologi/artikel/ nordens-velfaerd-hviler-paa-danske-skuldre: Altinget.

Orlikowski, W. J. (2000). "Using Technology and Constituting Structures: A Practice Lens for Studying Technology in Organizations", Organization Science, 11(4):404-428. doi: http://dx.doi.org/10.1287/orsc.11.4.404.14600.

Orlikowski, W. J. (2007). “Sociomaterial Practices: Exploring Technology at Work”, Organization Studies, 28(9):1435-1448. doi: http://dx.doi.org/10.1177/0170840607081138.

Rambøll (2012). Demonstrationsprojekt Ældre- og Handicapvenlige toiletter [Demonstrationproject - Elderly- and handicap-friendly toilets].

Shore, C. and Wright, S. (1997). "Policy: A new field of anthropology" in Shore, C. and Wright, S. (eds.) Anthropology of Policy: Critical Perspectives on Governance And Power, London: Routledge (European Association of Social Anthropologists): 3-42.

Shore, C. and Wright, S. (2011). "Conceptualizing policy: Technologies of governance and the politics of visibility" in Shore, C., Wright, S., Però, D., and European Association of Social Anthropologists (eds.) Policy Worlds: Anthropology and the Analysis of Contemporary Power, New York, NY: Berghahn Books (EASA series, 14). 
Stacey, C. L. (2005). "Finding dignity in dirty work: the constraints and rewards of low-wage home care labour", Sociology of Health \& Illness, 27(6):831-854. doi: http://dx.doi. org/10.1111/j.1467-9566.2005.00476.x.

Star, S. L. and Strauss, A. (1999). "Layers of Silence, Arenas of Voice: The Ecology of Visible and Invisible Work", Computer Supported Cooperative Work (CSCW), 8(1-2):9-30. doi: http://dx.doi.org/10.1023/A:1008651105359.

The Digitalisation Administration (2013). Danskernes holdning til digital velfærd [Danes' attitudes towards digital welfare].

The Government, Danish Regions, LGDK and The digitalisation administration (2013). Digital welfare, empowerment, flexibility and efficiency, common public sector strategy for digital welfare. 1. oplag, Copenhagen: The Danish Agency for Digitisation.

The Government and LGDK (2011). Aftale om kommunernes økonomi for 2012 [Agreement on municipal finances for 2012].

The Government and LGDK (2012). Aftale om kommunernes økonomi for 2013 [Agreement on municipal finances for 2013].

The Government and LGDK (2013a). Aftale om kommunernes økonomi for 2014 [Agreement on municipal finances for 2014].

The Government and LGDK (2013b). "Digitalisering og digital velfærd. Bilag til Aftale om kommunernes økonomi for 2014 [Digitalisation and digital welfare. Appendix to the agreement on municipal finances for 2014]."

The Government, LGDK and Danish Regions (2016). Et stærkere og mere trygt digitalt samfund. Den fællesoffentlige digitaliseringsstrategi 2016-2020 [A stronger and safer digital society. The common public sector digitalisation strategy 2016-2020].

The government, LGDK and Danish Regions (2013). Digitalisering med effekt - National strategi for digitalisering af sundhedsvæsenet 2013-2017 [Digitalisation with effect National strategy for digitalisation of the healthcare system 2013-2017].

Thiim, M. (2010). “ABT-fonden [The ABT Foundation]”, Økonomistyrelsen.

Twigg, J. (2000a). Bathing: The Body and Community Care, Florence, KY: Routledge.

Twigg, J. (2000b). "Carework as a form of bodywork", Ageing \& Society, 20(4):389-411. doi: http://dx.doi.org/10.1017/S0144686X99007801.

Twigg, J., Wolkowitz, C., Cohen, R. L. and Nettleton, S. (2011). “Conceptualising body work in health and social care", Sociology of Health and Illness, 33(2):171-188. doi: http:// dx.doi.org/10.1111/j.1467-9566.2010.01323.x.

Wolkowitz, C. (2002). “The Social Relations of Body Work”, Work, Employment \& Society, 16(3):497-510. doi: http://dx.doi.org/10.1177/095001702762217452.

Wærness, K. (1984). "The Rationality of Caring”, Economic and Industrial Democracy 5: 185-211. doi: http://dx.doi.org/10.1177/0143831X8452003.

Yachnin, D et al. (2017). "Can technology-assisted toilets improve hygiene and independence in geriatric rehabilitation? A cohort study”, Disability and Rehabilitation: Assistive Technology, Taylor \& Francis:1-8. doi: http://dx.doi.org/10.1080/17483107.2017.1358303. 